\title{
SHOCK IN THE NEWBORN INFANT
}

BY

\author{
R. A. MILLER, B.A., M.D., M.R.C.P.Ed.
}

(From the Department of Child Life and Health, The University of Edinburgh)

At the present day physicians and surgeons are more anxious than ever to understand the mechanism of shock, to estimate its gravity and to supply adequate treatment. Moon (1938) defined the condition as a circulatory deficiency, neither cardiac nor vasomotor in origin, characterized by a decrease in blood volume, a haemoconcentration and a fall in cardiac output. Beside these findings numerous other changes frequently occur; a tachycardia, a reduction in blood pressure, an initial rise in blood sugar followed by a rise in non-protein nitrogen and a fall in serum proteins, and lastly a fall of serum sodium and rise of the potassium. The behaviour of the chlorides is variable for there is probably a chloride shift as shown by the presence of a hypochloraemia in the serum and a hyperchloraemia in the blood corpuscles in cases of severe shock. It will now be shown that both the mother and her infant at the time of parturition frequently exhibit the above features no matter whether clinical shock is present or not.

Before giving an account of the present investigations on the blood chemistry, it is necessary to explain the omission of a record of the heart rate, blood pressure and the degree of haemocentration. The pulse rate is an unreliable guide to the presence of shock, for as McMichael (1941) points out the pulse rate in adults does not necessarily accelerate with the onset of shock, and if it should do so, it seldom exceeds 120 beats per minute irrespective of the gravity of the patient's condition. Similarly, in the newborn infant, the heart rate and in addition the blood pressure are of little value in detecting shock; in fact, such observations may be deceptive. For example, accurate determinations of the blood pressure are extremely difficult and the infant's pressure is raised by an unusual amount of trauma in the birth passages or hypertension in the mother (Rocker and Connell, 1924; Abt and Feingold, 1930; Reis and Chaloupha, 1923; Brown, 1933; and Woodbury et al., 1938). With regard to haemoconcentration, Moon (1938) states that it occurs before changes take place in the blood chemistry and that it is most easily determined by repeatedly enumerating the number of red cells per c.mm. of blood, or by estimating the haemoglobin content of the blood at intervals and comparing the results. In the newborn infant such results are open to criticism since the activity of the bone marrow is great and is liable to fluctuate considerably while the infant adapts itself to its new surroundings. In addition, the physiological haemolysis of the red 
cells at birth will also render haemoconcentration values inaccurate. Nevertheless, it is generally accepted that haemoconcentration does occur during the first three-and-a-half to forty-eight hours after birth, as the red cell count rises during this period (Lucas, 1921; Lippman, 1924; Merrit and Davidson, 1933; Konzelmann, 1934; and Rasi and Bollet, 1938), and subsequently falls. Therefore, a more reliable method of estimating shock must be sought.

\section{Method of investigation}

Details of the mother's age, pregnancies and health during the last pregnancy were taken. The details of the labour with special reference to the taking of fluid or food, the type of delivery and the duration of the labour were recorded. If the presentation of the infant was an occipito-anterior and birth occurred without the aid of instruments it was termed a spontaneous delivery, but if forceps were applied to the head the fact was indicated on the accompanying charts. Breech extractions and babies born by caesarian section have also been investigated. The type of anaesthetic given was light chloroform anaesthesia for all normal cases while the head of the infant was being born, but deep and prolonged anaesthesia was required for all instrumental and some breech deliveries. For mothers undergoing caesarian section, gas, oxygen and ether were administered. The above details on anaesthetics have not been charted, but in two cases information regarding twilight sleep and local anaesthesia which were used instead of the routine procedure have been recorded on the charts. Points of interest in the history of the foetus were abnormal foetal heart sounds and the presence of meconium in the liquor amnii, which have been interpreted as a sign of foetal distress. In order to assess the infant's vitality at birth, particular attention was paid to its colour, muscle tone, onset and character of respirations, and general behaviour. Caput succedaneum and moulding of the cranial bones were also looked for. Later, in the nursery, the infant's progress and weight were closely observed for at least ten days.

The response of the infant at birth has been constantly quoted in the results. For practical purposes four groups have been defined; the first consisted of infants which responded normally, that is their breathing, colour and vitality were satisfactory within four minutes of birth. Those infants which required five to ten minutes to attain normal standards were said to respond abnormally slowly. When resuscitation took ten to twenty minutes the response was considered to be very slow and shock was certainly present. The last, or fourth group of infants, included those whose condition was abnormal after twenty minutes. It was probable that such cases were not only suffering from severe shock but also from cerebral damage or pulmonary complications.

Specimens of blood for biochemical examination were obtained from the foetal circulation by cutting the umbilical cord and allowing the blood to run from the end attached to the placenta into a test tube. The blood was never taken until the cord had ceased to pulsate, but always within five minutes from the birth of the child. The maternal blood was then procured by venepuncture without delay, except in complicated deliveries when there was sometimes an 
interval of half an hour, owing to the inability to perform the venepuncture. When the babies were stillborn the blood had to be aspirated from the heart. The amount of clotted blood required was 7 to 10 c.c. and uncoagulated was 3 to 4 c.c. From these samples sugar was estimated by using $0 \cdot 2$ c.c. noncoagulated blood for the micro-modification of the Folin Wu technique. For the non-protein nitrogen and the serum protein determinations, the micro-Kjeldahl method was adopted and for the analysis 3 c.c. serum were used. The chlorides were estimated by the standard Van Slyke process, and the sodium colorimetrically.

\section{Results}

There were twenty-eight blood-sugar estimations upon the mother and fortyfour upon the newborn infant. The results are shown on table 1 where it is revealed that the blood-sugar in the mother was invariably higher than in her infant except in one instance when a craniotomy had been performed. There was, however, a wide range of normal as demonstrated by the following summary:-

\begin{tabular}{|c|c|c|c|c|}
\hline & & Yo, OF & BLOOD SUGAR & $\begin{array}{l}\text { AVERAGE } \\
\text { BLOOD SUGAR }\end{array}$ \\
\hline & & CASES & MGM. PER CENT. & MGM. PER CENT. \\
\hline Mother & & 28 & $90-229$ & 140 \\
\hline Infant: over $5 \frac{1}{2} \mathrm{lb}$. & - & . 25 & $79-190$ & $125 \cdot 4$ \\
\hline 3 to $5 \frac{1}{2} \mathrm{lb}$. .. & $\cdots$ & .. 10 & $82-166$ & $121 \cdot 6$ \\
\hline Under $3 \mathrm{lb} .$. & .. & .. & $38-69$ & 52 \\
\hline Stillbirths: over $5 \frac{1}{2} \mathrm{lb}$. & .. & .. & $49-82$ & 65 \\
\hline Craniotomy & $\ldots$ & .. & - & 48 \\
\hline Craniotomy & .. & .. 1 & - & 400 \\
\hline
\end{tabular}

The marked variation in the mother was dependent upon numerous factors; toxaemia of pregnancy, antepartum haemorrhage, excitement on the part of the mother during labour, prolonged labour and instrumental deliveries. These all tend not only to raise the mother's blood-sugar but also the infant's, either directly or indirectly. The influence of carbohydrate intake and anaesthesia could not be demonstrated. The relationship between the clinical condition of the baby and its blood chemistry is revealed by the fact that ten out of twenty-one infants, i.e. almost 50 per cent., with a blood-sugar of $110 \mathrm{mgm}$. per cent., or more were shocked at birth, whereas out of those with a lower bloodsugar only one in fourteen, i.e. 7 per cent., was shocked. It is interesting to see that although distressing signs have been noted in both mother and infant, most infants live and progress normally. Even the initial physiological loss of weight in infants with a high and a low blood-sugar is on the average approximately $7 \mathrm{oz}$. in each group.

The non-protein nitrogen of the blood depends upon the urea, amino-acid, creatinine, uric acid and residual nitrogen content in the blood; therefore, it is not surprising that its value varies considerably in mother and infant at the time of parturition (see table 2). In the forty mothers examined it ranged from 28 to $60 \mathrm{mgm}$. per cent. and the average was $37 \mathrm{mgm}$. In contrast to this the maximum and minimum values in forty-one infants were 24 and $64 \mathrm{mgm}$. respectively and their average was $40 \mathrm{mgm}$. The majority of the infants 
87.5 per cent., had higher values than their mothers, but this figure may be slightly inaccurate as the mothers who underwent caesarian section were the ones to have higher non-protein nitrogen than their babies, and it was also in these mothers that there was a delay in obtaining samples of blood. The prognostic significance may be summed up by stating that three out of seventeen infants, i.e. 18 per cent., with a non-protein nitrogen of less than $40 \mathrm{mgm}$. per cent. were shocked, while almost half the infants with a higher value exhibited shock. Nevertheless, the patients even with the maximum value of $64 \mathrm{mgm}$. generally made an uninterrupted recovery.

The serum protein, albumin and globulin in twenty-two mothers and their infants have been correlated with the clinical state of the infant at birth (see table 2). A summary of the figures is as follows :-

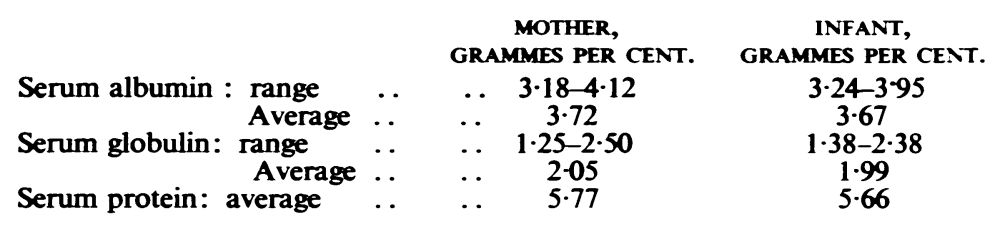

They are lower than in normal adults and this reduction is more marked in the albumin fraction than in the globulin fraction. The reduction is not only absolute but also relatively greater in the infant than in the mother. It should not be assumed from these figures that the maternal values are invariably higher than the infant's, since $\mathbf{4 4}$ per cent. of the infants had a higher albumin blood content than their respective mothers. The results of the serum albumin and total protein bore no relationship to the clinical picture of the infant, or to its weight progress. The globulin fraction, however, was of prognostic value. If it fell below 2.06 grammes per cent. in the mother or 2.0 in the infant there was foetal distress or subnormal vitality in nine out of eleven infants, i.e. 78 per cent., at birth. On the other hand only three out of eleven infants (27 per cent.), with a higher globulin exhibited subnormal activity at birth.

Little need be said about the serum sodium and plasma chlorides of the blood detailed in table 3 , as the latter does not influence the infant's general condition at birth, nor does it modify the infant's weight progress. The former, however, illustrates how a low serum sodium of $326 \mathrm{mgm}$. or less is associated with unmistakable signs of shock in 43.5 per cent. of such cases, i.e. seven out of sixteen cases. On the other hand, out of the fourteen infants with a higher value for the blood sodium only one ( 7 per cent.) was suffering from a similar degree of shock. A summary of the findings is given below:-

\begin{tabular}{|c|c|c|c|c|c|c|}
\hline & & & & MOTHER & & INFANT \\
\hline & & & CASES & MGM. PER CENT. & CASES & MGM. PER CENT. \\
\hline Serum sodium: & Range & $\cdots$ & . 29 & $\begin{array}{c}306-345 \\
322\end{array}$ & 29 & $\begin{array}{c}308-350 \\
326\end{array}$ \\
\hline Plasma chloride & : Range & $\cdots$ & $\begin{array}{l}\cdots \\
\cdots \quad 22\end{array}$ & $421-538$ & 23 & $351-468$ \\
\hline
\end{tabular}

These figures show how both these constituents of the blood are sometimes below the normal adult level. The sodium values are not predominantly 


\begin{tabular}{|c|c|c|c|c|c|c|c|c|}
\hline \multirow{2}{*}{ 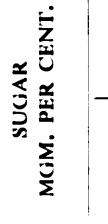 } & $\stackrel{2}{ٍ}$ & 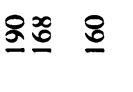 & $\nsubseteq \mathfrak{s}$ & 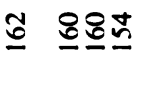 & 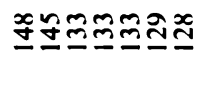 & $\cong$ & $\underline{\underline{a}} \bar{\beth}$ & 쁘으으으. \\
\hline & 童 & I ิㅗำ & 1 & | ठ్సిస్లి| & 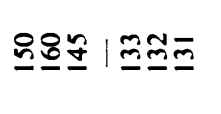 & $\cong$ & $\dot{\Xi} \bar{z}$ & 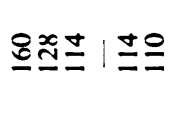 \\
\hline \multicolumn{2}{|l|}{ 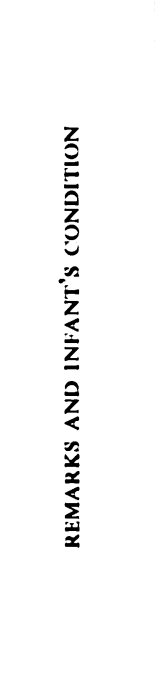 } & 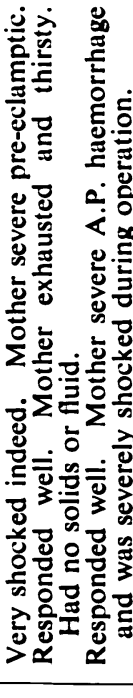 & 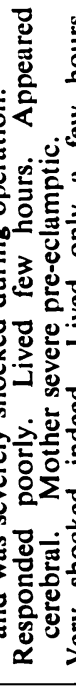 & 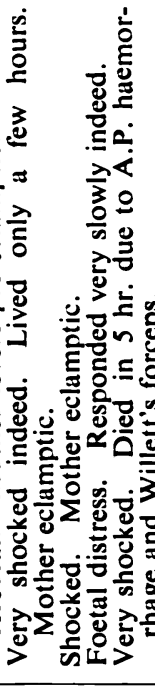 & 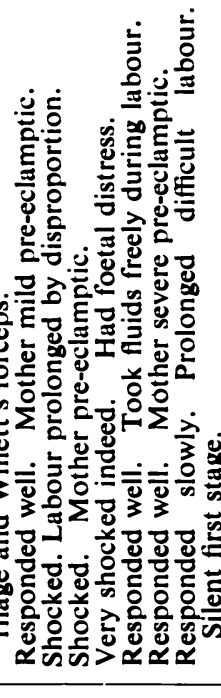 & 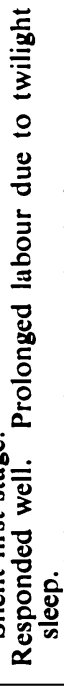 & 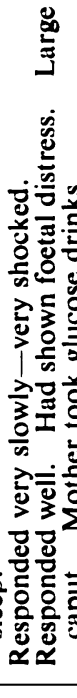 & 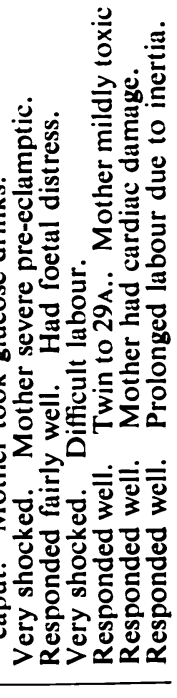 \\
\hline \multicolumn{2}{|l|}{ 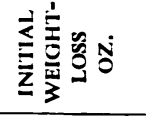 } & $-\underline{0}=$ & 1 & $1 \overrightarrow{0}=1$ & 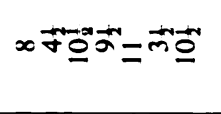 & $\vec{a}$ & $\operatorname{la}$ & DonNm̄o \\
\hline \multicolumn{2}{|l|}{ 产通 } & $\begin{array}{l}m \overrightarrow{0} m \\
\text { er } \quad\end{array}$ & $m$ & $\begin{array}{l}\sim x \simeq \mathbb{N} \\
\forall-x+\end{array}$ & $\begin{array}{l}\text { EmiñNNo } \\
\text { noenoen }\end{array}$ & $\begin{array}{l}0 \\
x\end{array}$ & $\begin{array}{l}x \geq \\
00\end{array}$ & $\begin{array}{l}\overrightarrow{0}=\mathbb{O} 0 \overrightarrow{0} 0 \\
m n x m+0\end{array}$ \\
\hline \multicolumn{2}{|l|}{ 竞 } & 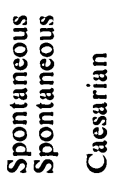 & 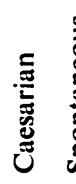 & 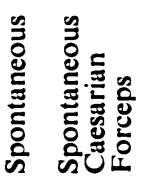 & 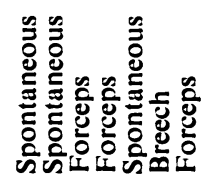 & 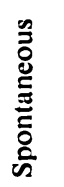 & 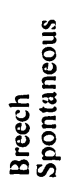 & 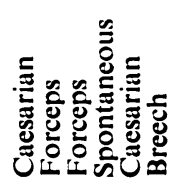 \\
\hline \multicolumn{2}{|l|}{ 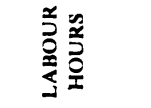 } & $\vec{d} \approx 0$ & 0 & $\sim \overrightarrow{0 ี \Omega \Xi}$ & 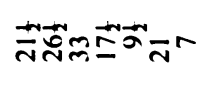 & ลิ & त्रत् & ดロ ีีทดก \\
\hline \multirow{2}{*}{ 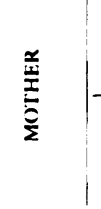 } & 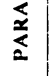 & mo $N$ & 0 & * NNO & 0000000 & 0 & 00 & $0000+0$ \\
\hline & $\stackrel{n}{\gtrless}$ & Y\& $\bar{\sigma}$ & $\bar{N}$ & 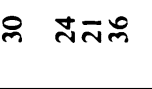 & 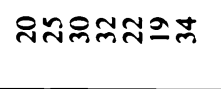 & $\tilde{N}$ & జึลิ & নম்రిలిళ゙ \\
\hline \multicolumn{2}{|l|}{$\underbrace{\text { }}_{\hat{⿱}}$} & 春品 & $\bar{\sim}$ & 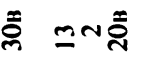 & $m-\underline{0} \underset{m}{ }+\infty$ & $n$ & ల్ల & - \\
\hline
\end{tabular}




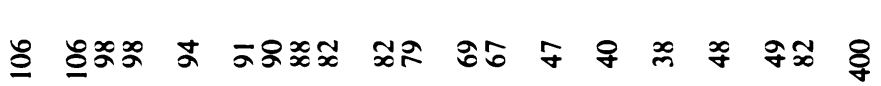

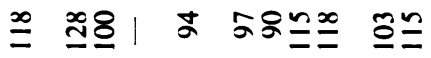

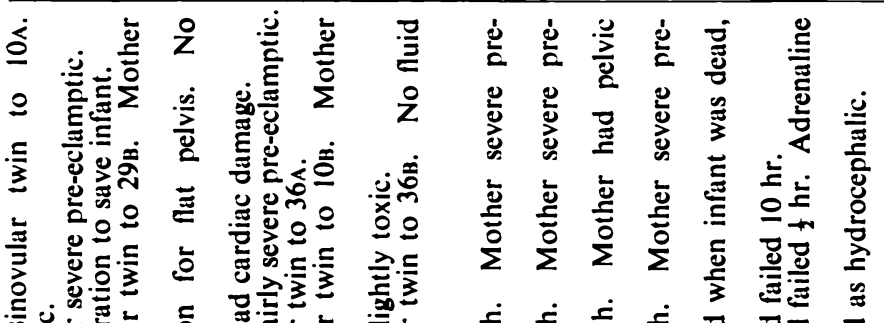

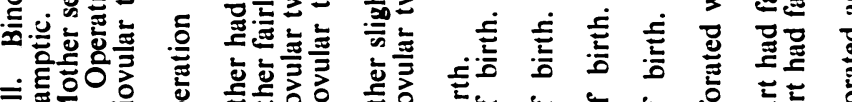

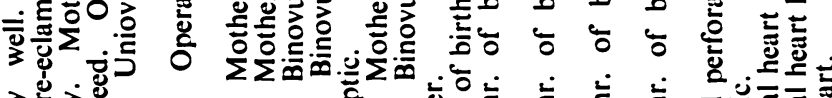

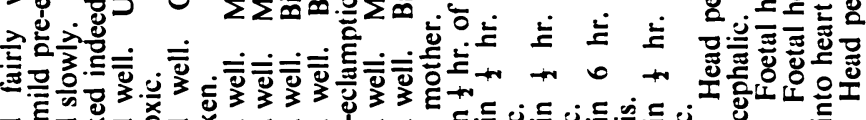

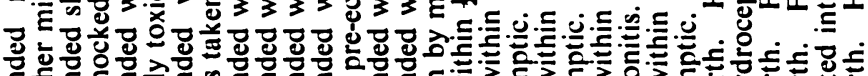

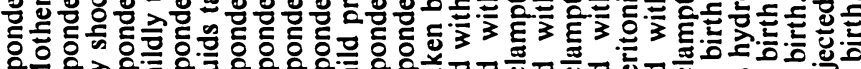

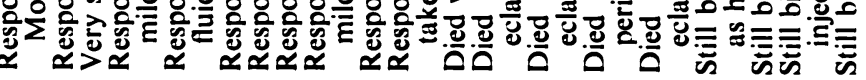

$=\infty 0-0$ Oีేบm |

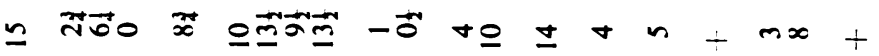

$n$ rnm o oorm no - N N - O n

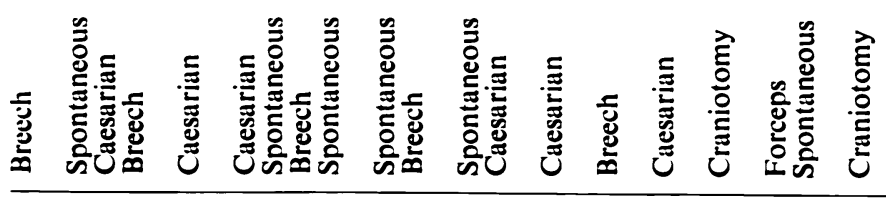

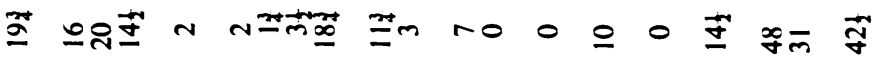

0000 - novo - no mo mo 000

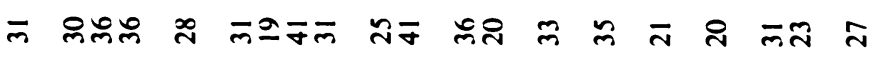

음ำ 


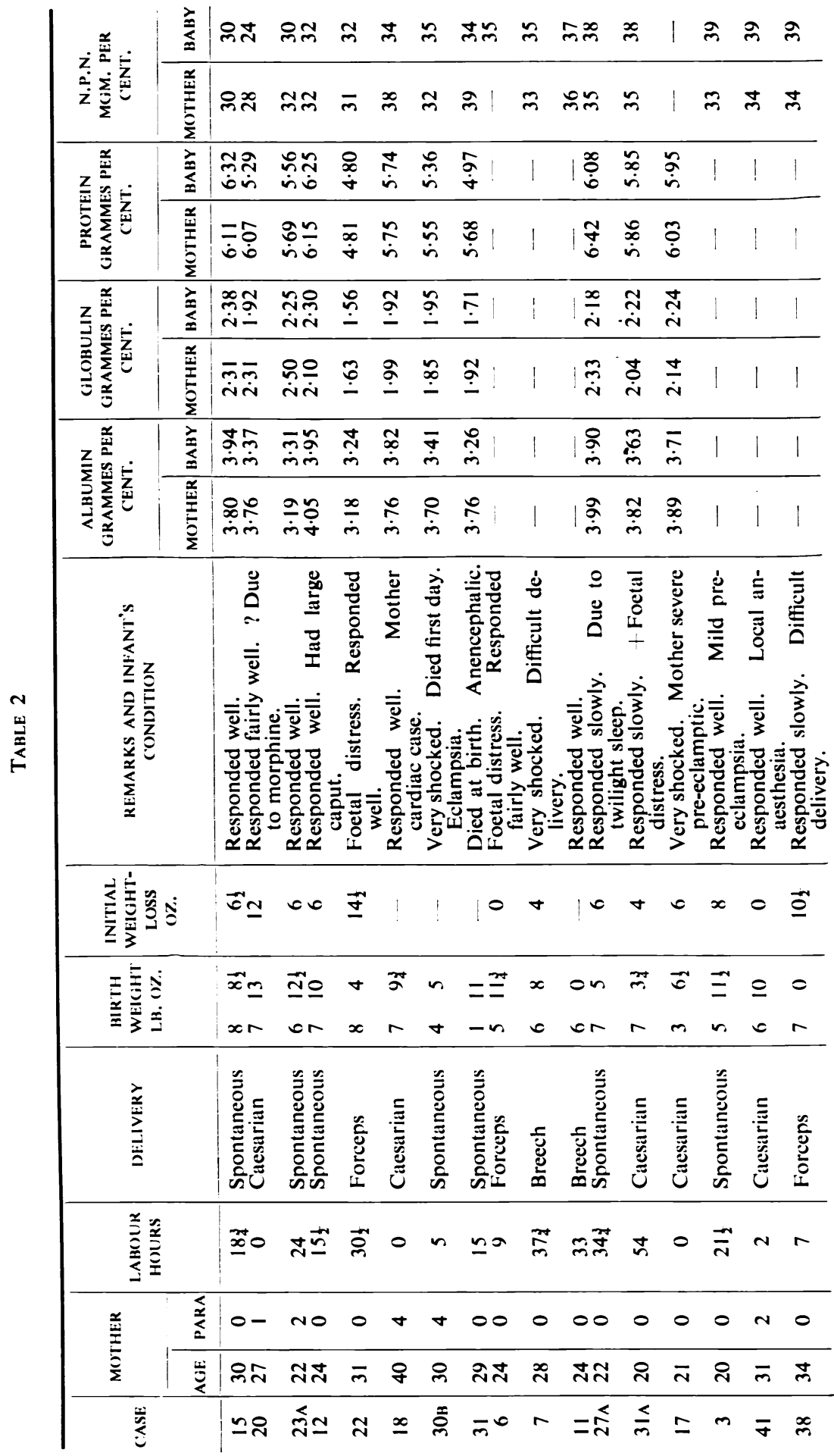




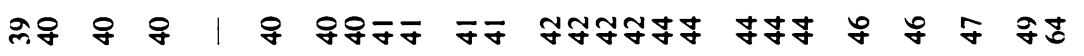

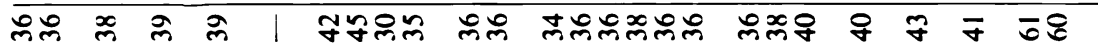

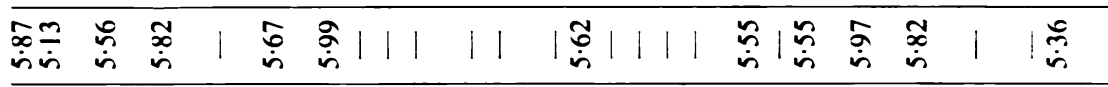

कीं

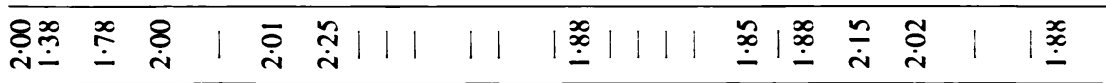

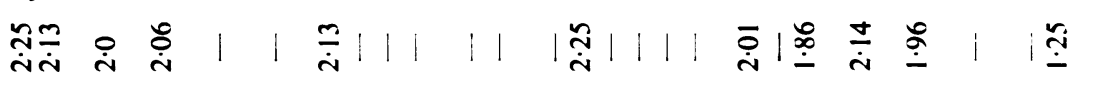

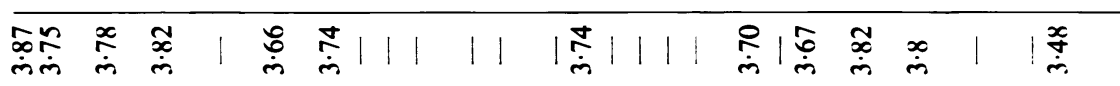

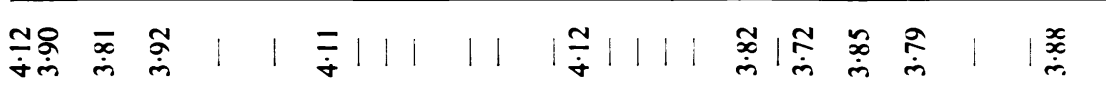

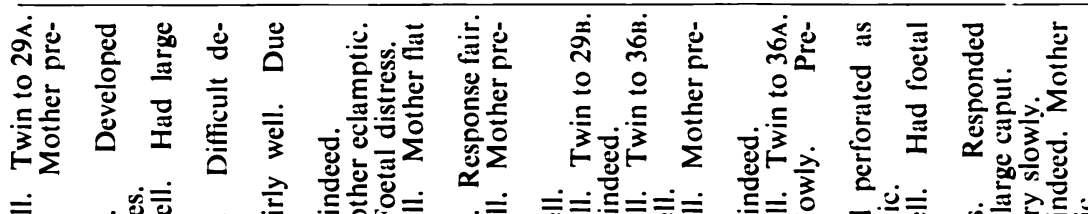

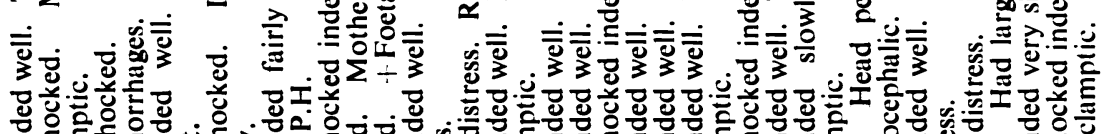

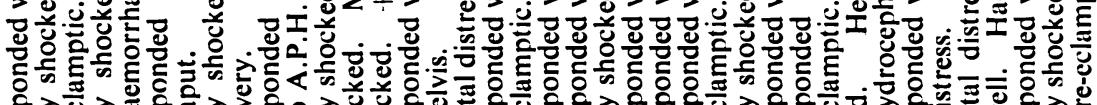

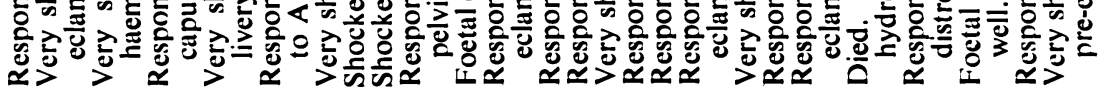

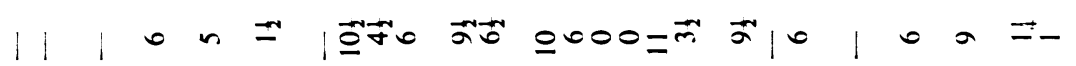

$x+0 \equiv \overrightarrow{0} m x x \vec{m}$ o

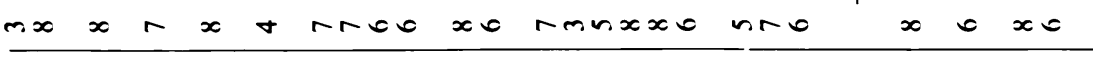

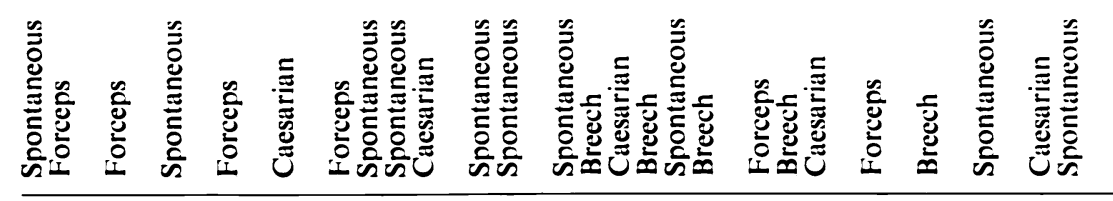

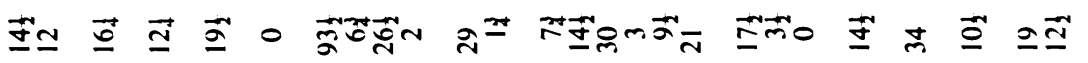

00000 n ono- 0000000000000 he

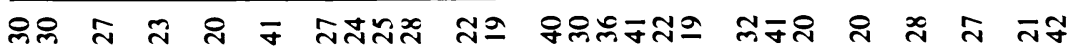

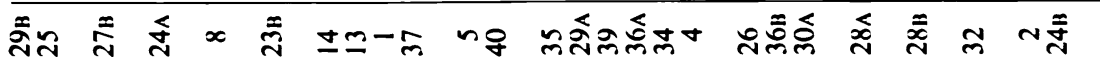




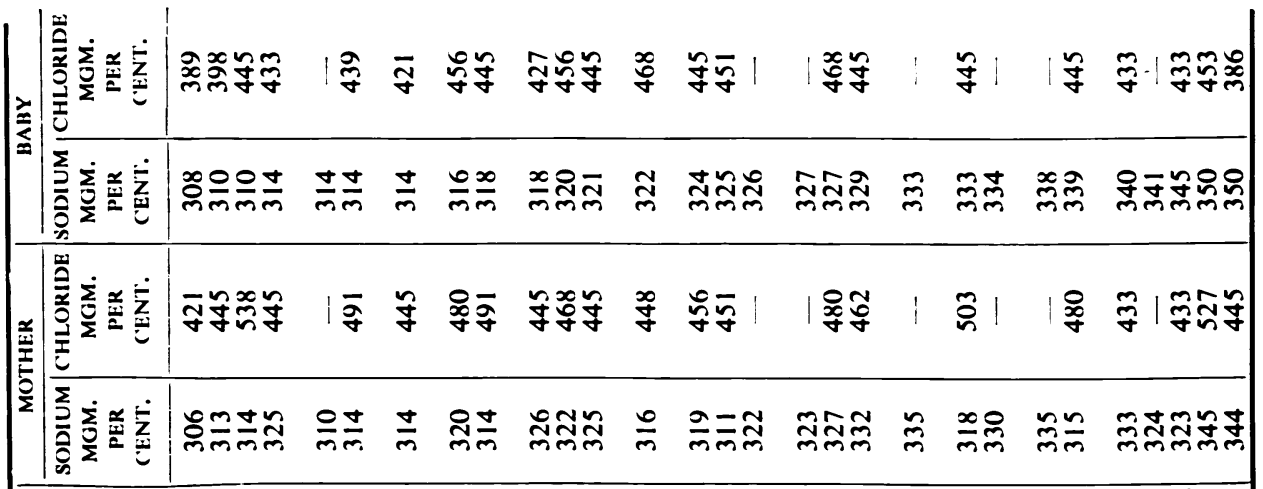

\begin{tabular}{|c|c|}
\hline 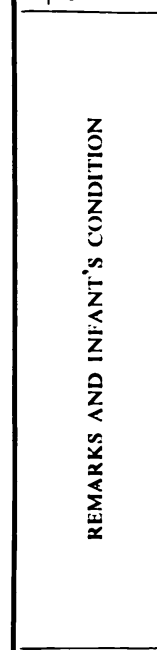 & 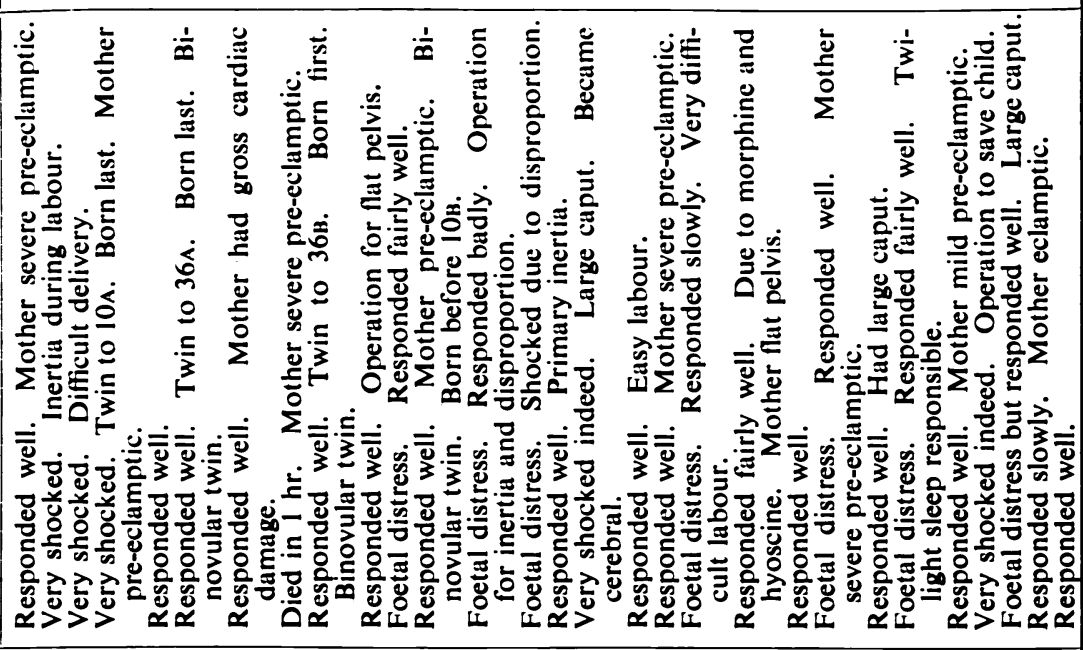 \\
\hline 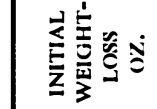 & $\vec{n}+n=\overrightarrow{0} 10$ \\
\hline 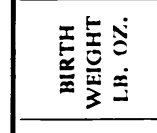 & 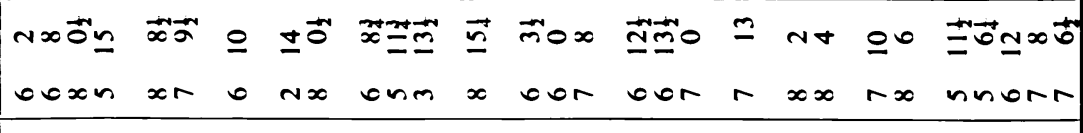 \\
\hline & 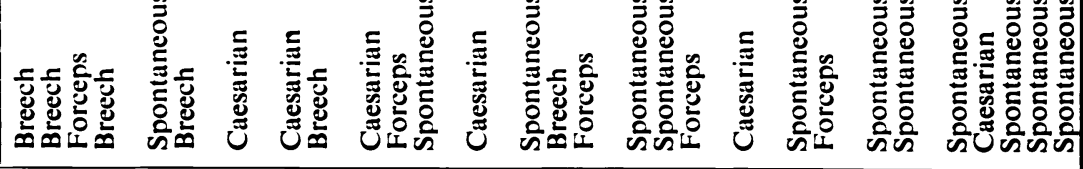 \\
\hline 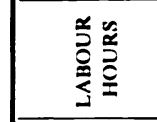 & 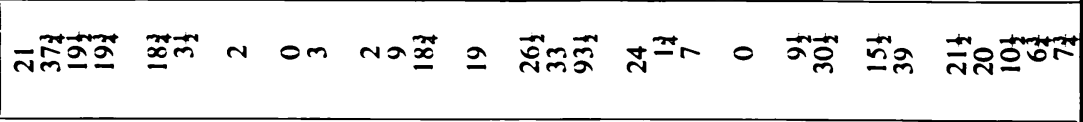 \\
\hline 善喜 & $000000 \times 00-00 \times 000 \times 100-00000$ \\
\hline 要 & 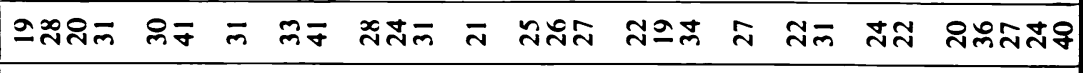 \\
\hline 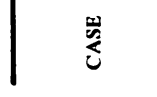 & \\
\hline
\end{tabular}


higher in the mother or the infant, in contrast to the chloride values, which were always higher in the mother with one exception in a case of caesarian section.

\section{Discussion}

The behaviour of the blood chemistry at birth will now be discussed under the headings of the various constituents which have been investigated. The results will be compared with those of other authors and an attempt will be made to state the factors responsible for the unexpected findings. Firstly, the blood-sugar levels have been shown in the past to be unusually high as compared with the fasting level in the normal adult. In the present series, values have been obtained which are on the average approximately $20 \mathrm{mgm}$. higher in both mother and infant than those recorded by previous authors.

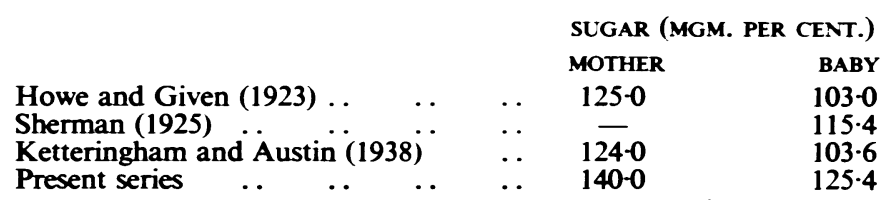

The higher level can only be accounted for by the introduction of results obtained from mothers suffering from toxaemia of pregnancy, ante-partum haemorrhage, unduly long labour and abnormal deliveries. This high figure is only temporary for Ketteringham and Austin (1938) state that the normal adult fasting level appears in infants three to six hours after birth. Factors known to be responsible for this phenomena are anaesthesia (Ketteringham and Austin, 1938) and those already mentioned, and they achieve this physiological process by liberating an abundant supply of adrenaline into the circulation. In addition hyperglycaemia may result from a diminished production of insulin kinase secondary to portal stasis or hepatic insufficiency, for Thompson and Wilkinson (1940) have shown that children suffering from severe burns or scalds may develop an abnormal laevulose tolerance test.

Hypoglycaemia in the newborn has seldom been recorded, and the present investigations show that infants with a blood-sugar of under $70 \mathrm{mgm}$. per cent. at birth do not live more than four hours. A suspected case reported by Ehrich (1934) was thought to be due to diabetes in the mother, but it is now shown that this is not the only cause. Prematurity probably plays an important part; five infants weighing less than $3 \mathrm{lb}$. all had hypoglycaemia and died soon after birth. Further evidence is given by Van Creveld (1929) who found hypoglycaemia frequently in premature infants during the first month of life. The fact that it is confined to the premature infant is an argument for the functional immaturity of the liver. Even in the mature infant the glycogen storage of the liver and the placenta may be relatively less than that in the mother, as her blood-sugar is invariably higher.

The present biochemical investigations reveal that the non-protein nitrogen is also exceptionally high in mother and infant, their average being 37 and $40 \mathrm{mgm}$. per cent. respectively. The values for infants approximate to those 
quoted by Lucas et al. (1921) and Bruch and McCune (1936). Their figures were 35 and $42 \mathrm{mgm}$., but the retention of the waste products of metabolism definitely decreases on the third day of life when the average values are 32 to 36 mgm. per cent. (Lucas et al., 1921; Bruch and McCune, 1936). Why this should happen and why the maternal values are not constantly lower than the infant's is unknown. If it were due to shock, the non-protein nitrogen would tend to be higher with increased trauma as is observed in the present cases. If trauma is a controlling factor either the mother or the infant can be subjected to the greater strain and therefore either person can have the maximum non-protein nitrogen. An additional factor modifying the results, might be a temporary renal impairment in the mother at parturition, as indicated by her raised urea nitrogen which is relatively greater than in the foetus (Howe and Given, 1923). Another possible explanation may be that the placental function alters during labour, causing an impairment in the excretion of the waste products of metabolism.

The serum proteins in the newborn are particularly low, as has been shown by previous investigators.

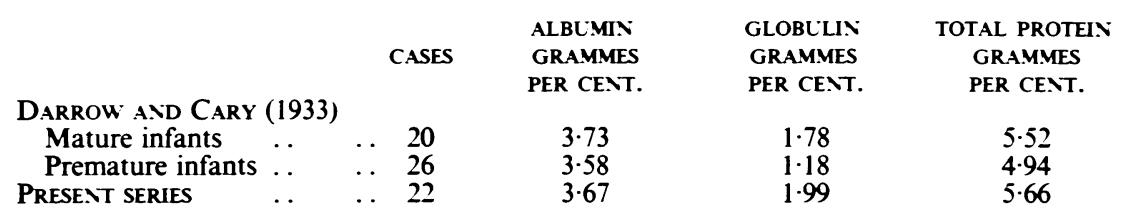

The total protein does not long remain low, for each day it rises until it is 6.23 grammes per cent. on the third day of life (Marples et al., 1932). Thereafter it rises gradually to attain adult levels by the eighteenth month of life (Rennie, 1935). The rapid initial rise in the amount of protein needs explaining. The subnormal values probably depend upon the state of development of the liver, which would account for the low values characteristic of the premature infant. The rapid rise of the serum proteins during the first three days of life may be due solely to the concentration of the blood, possibly precipitated by shock. Or it may be a physiological process to compensate for an exceptionally large blood-volume prior to birth. The latter possibility is supported by the observation of Oberst and Plass (1936) that the large blood-volume in the pregnant woman returns to normal or even subnormal at parturition; the foetal circulation may be similarly affected.

The sodium estimations gave results identical with those of the only similar investigation found in the English literature (Bruch and McCune, 1936). Bruch showed that the sodium rose from $325.7 \mathrm{mgm}$. per cent. at birth to $332.5 \mathrm{mgm}$. on the second day of life and thereafter altered only slightly. The low values in the mother and the infant compared with those in the normal adult may be interpreted as evidence either of shock or of adrenal insufficiency. The former suggestion is supported by the observation that marked shock is six times more frequent in infants with a serum sodium below $327 \mathrm{mgm}$. per cent. than in those with a serum sodium either equal to or greater than this amount. The only evidence of adrenal insufficiency is given by Miller (1941) 
who noted that the administration of desoxycorticosterone reduced the initial physiological loss of weight at birth. Archidmede (1940) obtained similar results by means of this hormone but in premature infants. The chloride of the blood in both mother and infant is also surprisingly low in some instances. This cannot be due to blood dilution or to alteration in the alkali reserve (Matter, 1931), so that no valid reason can be given to explain it.

\section{Conclusion}

The blood chemistry of both mother and infant is disturbed at the time of birth, and haemoconcentration occurs in the infant during the first three to forty-eight hours of life. The biochemical changes may be summarized as follows: There is normally a transient rise in the blood-sugar which is constantly greater in the mother; the non-protein nitrogen is also elevated in both mother and infant but the rise is more marked in the latter; the serum proteins and albumin are always below the average adult level, whereas the globulin factor occasionally attains the average normal figure for man. The diversion from normal is usually more pronounced in the infant than in the mother. Lastly, the sodium content and chloride content of the blood, though frequently within normal limits, are sometimes exceptionally low. This affects more noticeably the estimations of sodium in the mother and of chlorides in the infant.

In the discussion an attempt was made to explain these findings on a physiological basis. In the mother the only rational explanation appears to be shock, occurring with or without its clinical manifestations. The baby's blood chemistry is obviously influenced by the biochemical constituents of the mother's blood, but the sudden alteration in the infant's mode of living and the need for it to adapt itself to its new surroundings introduce modifying factors. It was also observed that it was far commoner to find infants shocked when the blood chemistry was grossly deranged than when it was normal. The question then arises as to why the blood changes in the infant which are compatible with shock are not always associated with the clinical signs of the condition. At present this is unanswered, but it is suggested that if in a normal delivery the constituents of the infant's blood are suggestive of shock the clinical picture of this condition will only develop should trauma to the infant during labour become excessive. It was also interesting to note that these marked disturbances can be present for two or three days without producing deleterious effects upon the infant.

From the investigations upon the blood-sugar, non-protein nitrogen, serum globulin and sodium the following conclusions can be drawn. Firstly, it can be said that it is better for an infant to have a blood-sugar less than $110 \mathrm{mgm}$. per cent. at birth, for in such circumstances its vitality rarely gives cause for anxiety. If hypoglycaemia should be present the prognosis is bad; the infant, if premature, was found to weigh less than $3 \mathrm{lb}$. and generally died within an hour of being born, but if the infant was mature, it was stillborn. Secondly, the non-protein nitrogen concentration in the infant's blood varied with the clinical condition, shock being present in 18 per cent. of infants with less than 
$40 \mathrm{mgm}$. of the constituent as compared with almost 50 per cent. in infants with a higher figure. Thirdly, the serum globulin was an even better guide to the infant's clinical condition at birth. If it fell below 2.06 grammes per cent. in the mother or $\mathbf{2 . 0}$ grammes in the infant there was foetal distress or subnormal vitality at birth in 78 per cent. of cases, but if the globulin was higher, only 27 per cent. were similarly affected. Lastly, if the blood sodium was less than $327 \mathrm{mgm}$. per cent. 43 per cent. of the infants suffered from a marked degree of shock, but if the values were higher a similar degree of shock appeared in only 7 per cent. of infants.

The present study on shock has been carried out under the auspices of the Kirk Duncanson Fellowship for Medical Research, The Royal College of Physicans of Edinburgh.

Thanks are due to Prof. Charles MacNeil and the obstetricians in charge of the wards in The Simpson Maternity Pavilion, The Royal Infirmary, Edinburgh, for allowing the investigations upon their patients. Thanks are also due to Sister Anderson and the nursing staff for assistance in collecting the material for this paper, and to S. L. Rae, of The Royal Hospital for Sick Children, Edinburgh, for carrying out all the biochemical estimations.

\section{REFERENCES}

Abt, A. F., and Fengold, B. F. (1930). Amer. J. Dis. Child., 40, 1285.

Archidmede, M. (1940). Ormoni, Turin, 2, 224.

Brown, J. E. (1933). Amer. J. Dis. Child., 46, 949.

Bruch, H., and McCune, D. J. (1936). Ibid., 52, 863.

Darrow, D. C., and Cary, M. K. (1933). J. Pediat., 3, 573.

Ehrich, W. (1934). Klin. Wschr., 13, 584.

Howe, M. F., and Given, H. H. (1923). Amer. J. Dis. Child., 25, 63.

Ketteringham, R. C., and Austin, B. R. (1938). Amer. J. med. Sci., 195, 318.

Konzelmann, F. (1934). Amer. J. Dis. Child., 47, 467.

Lippman, H. S. (1924). Ibid., 27, 473.

Londe, S. (1932). Ibid., 44, 110.

Lucas, W. P., et al. (1921). Ibid., 22, 525.

Marples, E., et al. (1932). Ibid., 44, 31.

Matter, A. (1931). Rev. Chil. Pediat., 2, 421.

McMichael, J. (1941). Edinb. med. J., 48, 160.

Merritt, K. K., and Davidson, L. T. (1933). Amer. J. Dis. Child., 46, 990.

Miller, R. A. (1941). Arch. Dis. Childh., 16, 113.

Moon, V. H. (1938). Shock and related capillary phenomena, New York.

Oberst, E. W., and Plass, E. D. (1936). Amer. J. Obstet. Gynec., 31, 61.

Rasi, F., and Bollet, M. (1938). Riv. di clin. pediat. 36, 605.

Reis, R., and Chaloupha, A. J. (1923). Surg. Gynec. Obstet., 37, 286.

Rennie, J. B. (1935). Arch. Dis. Childh., 10, 415.

Rocker, M. P., and Connell, K. W. (1924). Amer. J. Dis. Child., $27,6$.

Scudder, J. (1940). Shock: Blood studies as a guide to therapy, Phila., 13, 96.

Sherman, D. H., et al. (1925). Amer. J. Dis. Child., 30, 497.

Thompson, J. C., and Wilkinson, A. W. (1940). Edinb. med. J., 37, 250.

Van Creveld, S. (1929). Amer. J. Dis. Child., 38, 925.

Woodbury, R. H., et al. (1938). Amer. J. Physiol., 122, 472. 